\title{
ASTERACEAE YANG DIMANFAATKAN SEBAGAI TUMBUHAN OBAT DI KECAMATAN LUBUK ALUNG KABUPATEN PADANG PARIAMAN
}

\author{
Yolanda Sari \\ Program Studi Pendidikan Biologi STKIP PGRI Sumatera Barat \\ Corresponding Auhor: \\ yolandasaari123@gmail.com
}

\begin{abstract}
ABSRTACT
The use of plants by traditional communities is examined in ethnobotany studies. Ethnobotany is the study of the relationship between people in a region and plants or the interaction of local people with their environment, especially plants. The use of plants as medicines by the community, one of which is in the area of Jorong Indarung Kanagarian Aie Tajun, Lubuk Alung Regency, Padang Pariaman District. Indarung Jorong community uses plants as traditional medicine consisting of single drugs and medicinal herbs. Knowledge of medicinal plants is obtained from people who know about medicinal plants (shamans) in the area. This research uses descriptive method with observation and direct interview techniques. Observations are made by direct observation to the field and sampling according to the required criteria and interviews are conducted directly with the experts of medicinal plants (shamans) in the Indarung Kanagarian Aia Tajun. Data on how to use medicinal plants by the community is presented in table form. From the results of research on ethnobotany, medicinal plants in Jorong Indarung Kanagarian Aia Tajun, Lubuk Alung Regency, Padang Pariaman District, found as many as 106 species of medicinal plants consisting of 49 families that can treat 32 kinds of diseases. The most widely used part of medicinal plants is leaves with a percentage of $45.98 \%$. The use of medicinal plants is used as an external medicine and internal medicine. The most commonly used internal medicine is taken while the external drug is the most widely used method, which is applied or applied.
\end{abstract}

Keywords : Etnobotany, Medicinal Plant, Jorong Indarung

\section{PENDAHULUAN}

Indonesia kaya dengan berbagai jenis flora, dari 40 ribu jenis flora yang tumbuh di dunia, 30 ribu diantaranya tumbuh di Indonesia, sekitar 26\% telah dibudidayakan dan sisanya sekitar 74\% masih tumbuh liar di hutan, dari yang telah dibudidayakan lebih dari 940 species digunakan sebagai obat tradisional (Syukur dan Hernani, 2003). Sesuai dengan pendapat Natoatmojdo (2011) Tumbuhan di Indonesia diketahui memiliki keragaman hayati terbesar setelah Brazil. Dari berbagai penelitian menyebutkan, terlihat dari 30.000 species tumbuhan di Indonesia sebanyak 6.000 jenis berkhasiat obat.

Pemanfaatan tumbuhan oleh masyarakat secara tradisional dikaji dalam kajian etnobotani. Etnobotani sebagai sains yang mempelajari tentang alam atau hubungan tradisional antara manusia dengan tumbuhan disekitar mereka. Etnobotani mencakup semua hubungan material, budaya, medis, dan reliqius orang-orang dengan tanaman dalam suatu ekosistem (Des, dkk). Etnobotani juga dapat dijadikan salah satu alat untuk mendokumentasikan pengetahuan 
masyarakat tradisional (Suryadarma, 2008). Nenek moyang Indonesia sejak dahulu telah menekuni pengobatan dengan pemanfaatan aneka tumbuhan yang ada di alam (Muslihah, 2007). Tradisi pengobatan suatu masyarakat tidak terlepas dari kaitan budaya setempat. Suku minangkabau adalah salah satu suku yang terdapat di provinsi Sumatera Barat, pengobatan dengan menggunakan ramuan dari tumbuhan telah dilakukan oleh suku minang sejak dahulunya. Di kota Pariaman masyarakat telah memanfaatkan 10 species tumbuhan magrove sebagai obat-obatan (Leilani, Rizki, Sari, Sari, 2017). Pemanfaatan tumbuhan sebagai obat ini tidak hanya pada tumbuhan teresterial saja, namun tumbuhan-tumbuhan yang hidup di perairan, seperti tumbuhan familia Rhizophoraceae yang tumbuh di hutan mangove di Teluk Buo Padang yang dimanfaatkan sebagai tumbuhan obat (Rizki, \& Leilani, 2018), begitu juga di hutan mangrove yang terdapat di kota Pariaman (Milda, Leilani, \& Rizki, 2012). salah satu daerah di Padang Pariaman yang masih memanfaatkan tumbuhan sebagai obat adalah jorong Indarung kenagarian Aia Tajun kecamatan Lubuk Alung Kabupaten Padang Pariaman.

Penggunaan tanaman obat selama ini sudah menjadi kebiasan oleh masyarakat di Jorong Indrung ini. Tanaman obat yang didapatkan terdiri dari banyak familia yang ada. Seperti yang terlihat pada hasil yang didapatkan oleh Efrimella (2015) yang menyatakan bahwa tumbuhan obat yang ditemukan atau dimanfaatkan oleh masyarakat desa Kayu Tanam sebanyak 50 spesies dari 32 famili. Salah satu familia yang paling banyak diguakan untuk bahan obat tradisional oleh masyarakat Jorong Indarung adalah familia Asteraceae.

Asteraceae adalah tumbuhan yang dapat dengan mudah kita temui disekitar lingkungan yang biasa kita datangi atau disekitar pekarangan rumah kita. Selain itu species dari familia Asteraceae ini banyak digunakan untuk pengobatan karena adanya kandungan tertentu yang terdapat di dalam tumbuhan familia ini. Seperti yang dijelaskan oleh Anjelina (2017) familia Asteraceae memiliki komponen senyawa bioaktif, seperti seskuiterpen, lakton, triterpen pentasiklik, alkohol, tanin, polifenol, saponin, dan sterol yang dapat digunakan untuk bahan pengobatan.

\section{METODE PENELITIAN}

Penelitian ini menggunakan metode deskriptif dengan teknik observasi dan wawancara langsung. Observasi dilakukan dengan pengamatan langsung ke lapangan dan pengambilan sampel sesuai dengan kriteria yang dibutuhkan dan wawancara dilakukan langsung dengan ahli tumbuhan obat (dukun) yang ada di jorong Indarung Kanagarian Aia Tajun.

\section{HASIL DAN PEMBAHASAN}

Tabel 1. Jenis-jenis tumbuhan dari familia Asteraceae yang dimanfaatkan untuk obat.

\begin{tabular}{llllll}
\hline No & Species & $\begin{array}{l}\text { Nama daerah } \\
\text { /nama umum }\end{array}$ & $\begin{array}{l}\text { Bagian yang } \\
\text { digunakan }\end{array}$ & $\begin{array}{l}\text { Penyakit dan } \\
\text { dapat diobati }\end{array}$ & Cara pemakaian \\
\hline 1. & $\begin{array}{l}\text { Acmella uliginosa } \\
\text { (Sw.) Cass. }\end{array}$ & $\begin{array}{l}\text { Bungo subang } \\
\text { / jotang kecil }\end{array}$ & Bunga & Sakit gigi* & Tempelkan \\
$\begin{array}{l}\text { 2. Adenostemma lavenia } \\
\text { L. }\end{array}$ & Cirik babi & Daun & Batuk, demam** & Peras, minum \\
3. Ageratum conyzoides & $\begin{array}{l}\text { Siamih/ } \\
\text { babodotan }\end{array}$ & Daun & Luka $*$ & Oles, tempelkan
\end{tabular}




\begin{tabular}{|c|c|c|c|c|c|}
\hline 4. & $\begin{array}{l}\text { Blumea balsamifera } \\
\text { (L.) DC. }\end{array}$ & Capo 1/ capo & Daun & Influenza* & Peras, minum \\
\hline 5. & $\begin{array}{l}\text { Elephantopus scaber } \\
\text { L. }\end{array}$ & $\begin{array}{l}\text { Tutup bumi/ } \\
\text { tapak liman }\end{array}$ & Daun & Diare* & Peras, minum \\
\hline 6. & $\begin{array}{l}\text { Enhydra fluctuans } \\
\text { Lour. }\end{array}$ & Cikarau & Daun & Demam ** & Peras, minum \\
\hline 7. & $\begin{array}{l}\text { Melampodium } \\
\text { divaricatum } \mathrm{L} .\end{array}$ & $\begin{array}{l}\text { Bunga } \\
\text { matahari kecil }\end{array}$ & Bunga & Demam ** & Peras, minum \\
\hline 8. & Plucea indica $\mathrm{L}$. & Capo 2/ capo & Daun & Demam * & Peras, minum \\
\hline 9. & Tagetes erecta L. & $\begin{array}{l}\text { Bungo cik } \\
\text { ayam /bunga } \\
\text { tahi kotok }\end{array}$ & Daun & Kanker payudara* & Peras, minum \\
\hline 10. & Vernonia amygdalina & Daun afrika & Daun & Darah tinggi* & Peras, minum \\
\hline 11. & Zinnia elegans Jacq. & $\begin{array}{l}\text { Bunga } \\
\text { kembang } \\
\text { kertas }\end{array}$ & $\begin{array}{l}\text { Semua } \\
\text { bagian }\end{array}$ & Disentri $*$ & Peras, minum \\
\hline
\end{tabular}

*: Tumbuhan yang dipakai sebagai obat tunggal

**: Tumbuahn yang dipakai sebagai ramuan obat

Berdasarkan penelitian yang dilakukan ditemukan 11 species dari familia Asteraceae yang berkhasiat obat yang dapat mengobati 12 jenis penyakit. Berikut adalah cara pengolahan tumbuhan familia Asteraceae.

\section{Acmella uliginosa $\mathrm{L}$.}

Tumbuhan Acmella uliginosa L. merupakan tumbuhan yang digunakan untuk obat luar yaitu untuk mengobati sakit gigi. Cara pengolahannya yaitu ambil satu buah bunga Acmella uliginosa L. (subang-subang) kemudian masukkan atau tempelkan pada gigi yang sakit (berlubang), tunggu beberapa saat (diamkan) setelah itu keluarkan dan kumur-kumur dengan air.

Hal ini sesuai dengan penelitian yang dilakukan oleh Sukarno (2014) yang berjudul Asteraceae Plant Species At Mataue, Lore Lindu National Park yang juga menjelaskan bahwa salah satu familia Asteraceae yaitu Acmella uliginosa L. dapat dijadikan sebagai obat sakit gigi. Namun hal ini berbeda dengan penelitian yang dilakukan oleh Maymulyanti (2015) yaitu tentang Chemical Composition Phytochemical Screening and Antioxidant Activity of Acmella uliginosa (Sw) Cass Leaves yang menyatakan bahwa bagian dari tumbuhan Acmella uliginosa L. Yang digunakan untuk obat lebih baik yaitu daun karena komponen dalam daun Acmella 
uliginosa menggunakan pelarut metanol, etil asetat dan n-heksana. Persentase hasil ekstrak dari daun dalam metanol, etil asetat dan n-heksana adalah 6,50, 0,49, dan 0,66, masing-masing.

\section{Adenostemma lavenia $\mathrm{L}$.}

Tumbuhan Adenostemma lavenia L. digunakan untuk obat dalam yaitu obat batuk dan demam. Dimana cara pemakaiannya yaitu dengan cra diminum. Cara pengolahan tumbuhan ini untuk obat batuk yaitu ambil daun Adenostemma lavenia L. (cirik babi) segenggam, peras menggukan satu gelas air kemudian tambahkan satu buah Citrus aurantifolia L. (jeruk nipis) tiriskan lalu minum dua kali sehari yaitu setiap pagi dan malam. Sedangkan untuk obat demam hanya perlu diperas saja lalu tiriskan tampa penambahan dengan bahan yang lain.

Hal ini sama dengan penelitian yang dilakukan oleh Kusumawati (2003) yang menjelaskan bahwa manfaat tumbuhan Adenostemma lavenia yaitu untuk obat batuk dan juga dijadikan sebagai ramuan obat namun dalam hal cara pengolahan dan penambahan bahan lainnya berbeda. Adapun cara pengolahan yang dilakukannya yaitu akar tumbuhan ini dikunyah dengan pinang dan ditambhakan sedikit jahe sehingga dapat mengobati batuk. Tidak hanya itu, daun dari tumbuhan ini mempunyai manfaat yang cukup banyak diantaranya daun yang ditambahkan dengan sedikit garam dan di peras dengan menggunakan air dapat mengobati sakit tenggorokan, daun yang dilayukan diatas api dapat memantangkan bisul, serta daun yang di peras dapat digunakan untuk menyejukkan kulit.

\section{Ageratum conyzoides L.}

Species ketiga dari familia Asteraceae ini digunkan untuk obat luaran yaitu untuk mengobati luka. Dimana cara pengolahannya yaitu ambil beberapa helai daun Ageratum conyzoides L. (siamih) kemudian tumbuk dan haluskan, setelah halus oleskan atau tempelkan dibagian tubuh yang terkena luka.

Hasil yang sama juga ditemukan oleh Tambaru (2017) yang melakukan penelitian tentang Keragaman Jenis Tumbuhan Obat Indigenous Di sulawesi selatan yang menjelaskan daun tumbuhan Ageratum conyzoides berkhasiat sebagai obat magh, sakit tenggorokan dan demam serta cara pengolahannya untuk luka diperas atau tumbuk dan tempelkan sedangkan untuk magh, peras dengan air sedikit lalu tambahkan madu dan minum.

Menurut Gbamosi (2012), siamih atau babodotan mengandung senyawa alkanoid, saponin, tanin, flavonoid, dan glikosida senyawa tersebut berfungsi sebagai antibakteri, antiinflamasi dan obat kumur.

\section{Blumea balsamifera (L.) DC.}

Tumbuhan Blumea balsamifera (L.) DC. Digunakan oleh masyarakat Jorong Indarung sebagai obat luar yaitu untuk influenza. Cara pengolahan tumbuhan ini yaitu gunakan satu helai 
daun lalu lipat menjadi bagian yang lebih kecil hingga muat dilubang hidung kemudia masukkan ke dalam lubang hidung sebagian lalu diamkan beberapa saat dan angkat setelah terasa lebih baik.

Berbeda dengan hasil yang ditemukan oleh Riswan (2008) yang melakukan penelitian tentang Keanekaragaman Tumbuhan Obat Yang Digunakan Dalam Pengobatan Tradisional Masyarakat Sasak Lombok Barat, di daerah Lombok Barat masyarakat menggunakan Blumea balsamifera (L.) DC. Bukan untuk obat flu melanikan untuk obat demam dengan cara dimandikan. Beliau juga menjelaskan bahwa daun dari tumbuhan capo ini mengandaung borneol, cineole, limonene, di-methyl ether phloroacetophenone dan dimanfaatkan untuk obat rematik, influenza, kembung, dan diare seta haid.

\section{Elephantopus scaber L.}

Tutup bumi atau yang biasa dikenal dengan nama tepak liman ini adalah salah satu tumbuhan yang digunakan untuk obat dalam dengan cara pemakaian diminum untuk mengobatai demam. Cara pengolahannya yaitu ambil daun tapak liman secukupnya lalu keringkan. Setelah kering ambil 15-30 gr daun kemudian rebus hingga mendidih dengan 2 gelas air tunggu sampai satu gelas kemudian tiriskan lalu minum. Hal ini sama dengan penelitian yang dilakukan oleh Sari (2015) tentang Pemanfaatan Tumbuhan Obat Pada Masyarakat Suku Dayak Jangkang Tanjung Di Desa Ribau Kecamatan Kapuas Kabupaten Sanggau masayarakat sama juga menggunakan tumbuhan Elephantopus scaber sebagai obat untuk demam.

\section{Enhydra fluctuans Lour.}

Tumbuhan Enhydra fluctuans Lour. biasa dikenal di sumatra dengan nama sikarau. Sikarau digunakan untuk ramuan obat dalam yaitu untuk mengobati penyakit demam dengan pemakaiannya yaitu diminum. Cara pengolahananya sendiri yaitu daun sikarau dan daun sidingin (Kalanchoe pinnata (Lmk.) Pers.) diperas dengan menambahkan air secukupnya. Kemudian ambil umbuik pisang batu (Musa paradisiaka L.) dipotong kecil-kecil dan dimasukkan kedalam perasan air sikarau dan sidingin tadi lalu airnya ditiriskan dan diminum setiap pagi setelah makan.

Berbeda dengan cara pengolahan yang dilakukan oleh Fernando (2014) yaitu menggunakan dain sikarau sebagai ramuan obat untuk obat luaran yang juga digunakan untuk mengobati demam. Dimana cara pengolahannya sendiri yaitu daun cikarau ditambah dengan umbuik pisang batu sepanjang sejengkal, daun sidingin secukupnya, daun cikumpai segenggam dan daun sitawa sekucupnya. Semua bahan diharuskan dan dioleskan diseluruh tubuh. 


\section{Melampodium divaricatum $\mathrm{L}$.}

Bunga matahari mini atau bunga matahari kecil ini tebih terkenal sebagai tumbuhan hias dengan keindahan corak warna yang dimilikinya. Namun ada sebagian masyarakat menggunakan tumbuhan Melampodium divaricatum L. ini sebagai ramuan obat dalam yaitu untuk obat penurun panas atau demam. Cara pengolahan tumbuhan ini sendiri yaitu ambil bunga sebanyak 7 buah bunga lalu tambahkan dengan daun belimbing wuluh (Averrhoa bilimbi L.) segenggam lalu peras bersamaan hingga didapatkan sari pati dari kedua tumbuhan tersebut, tiriskan lalu minum.

Berbeda dengan hal yang ditemukan oleh Rizki (2017) yang mendapatkan data bahwa tumbuhan ini digunakan oleh masyarakat untuk mengobati luka. Proses pengolahannya sendiri dilakukan dengan cara menghaluskan atau menumbuk daun secukupnya kemudian tempelkan atau oleskan pada bagian tubuh yang luka.

\section{Plucea indica $\mathrm{L}$.}

Tumbuhan Plucea indica L. ini dikenal dengan nama daun Capo. Daun capo ini di indonesia di kenal dengan nama beluntas yang digunakan sebagai obat dalam yaitu untuk mengobati penyakit demam. Cara pengolahannya yaitu ambil 7 helai daun capo kemudian rebus dengan menambhakan air secukupnya lalu tiriskan dan tunggu sampai hangat dan minum setiap pagi dan malam hari.

Sesuai dengan pendapat (Riani, 2013) yang menyatakan bahwa daun beluntas biasanya digunakan oleh masyarakat untuk menghilangkan bau badan, meningkatkan nafsu makan, mengatasi nyeri pada persendian, nyeri otot dan nyeri saat haid, menurunkan panas (demam) dan mengeluarkan keringat. Berbeda dengan obat demam yang menggunakan daun beluntas yang diperas kemudian diminum, dalam mengobati nyeri masyarakat biasanya menggunakan bagian akar dari beluntas sebanyak 10-15 gr direbus dengan air dan kemudian minum.

\section{Tagetes erecta $\mathrm{L}$.}

Bunga taik ayam atau lebih dikenal dengan bunga tahi kotok ini adalah jenis tumbuhan yang digunakan untuk mengobati kanker payudara dengan cara diminum. Dimana cara pengolahannya sendiri sangat sederhana yaitu ambil daun Tagetes erecta L. sebanyak 7 ranting tambahkan dengan air sebanyak satu gelas kemudian reus hingga mendidih setelah itu tiriskan dan minum selagi hangat. Berbeda dengan penggunaan tumbuhan tahi kotok yang di jeskan oleh Boesri (1994) yang menyatakan bahwa daun tahi kotok mengandung zat aktif yang terdiri dari saponin dan flofonoida yang dapat digunakan untuk obat malaria.

\section{Vernonia amygdalina $\mathrm{L}$.}


Tumbuhan Vernonia amygdalina L. dikenal dengan nama daun afrika yang dipercaya dapat digunakan sebagai bahan untuk obat dalam yaitu menurunkan darah tinggi. Cara pengolahannya yaitu ambil daun afrika sebanyak 7 helai atau lebih kemudian peras dengan menggunakan iar secukupnya lalu tiriskan dan minum setiap pagi dan malam hari. Menurut Sukmawati (2017) senyawa kimia yang terkandung dalam daun Afrika antara lain flafonoid, alkanoid, saponin, terpeniod, tanin, glikosida, alkaloid indole, antrakuinon dan luteolin yang dapat digunakan untuk obat anti kanker, penurunan panas (demam), mencegah stoke dan penurunan gula darah.

\section{Zinnia elegans Jacq}

Bunga kembang kertas ini adalah salah satu dari familia Asteraceae yang dapat dengan mudah kita temui dimana saja karena mayoritas masyarakat menanamnya disekitar pekarangan karena bunganya yang begitu indah. Tidak hanya memiliki keindahan bunga kemabang kertas (Zinnia elegans L.) ini juga digunakan masyarakat sebagai bahan untuk obat dalam yaitu untuk mengobati disendtri. Cara pengolahannya sendiri yaitu ambil bunga tumbuhan ini secukupnya lalu rebus dengan air hingga mendiidih kemudian tiriskan dan minum.

Sesuai dengan pendapat Jabar (2014) yang menyatakan bahwa tumbuhan ini digunakan untuk mengobati kencing nanah, disentri, bisul dan sakit pada papilea mamae. Penggunaannya untuk bisul dan sakit pada papilia mamae dilakukan dengan cara pengobatan luar yaitu digiling dengan halus lalu tempelkan pada bagian yang sakit. Sedangkan untuk pengobatan disentri pengolahannya dengan cara direbus semua bagian tumbuhan ini kemudian tambahkan dengan gula aren, lalu tambahkan air sebanyak 2 gelas dan didihkan hingga menjadi saru gelas air, tiriskan dan minum dua kali sehari. Unuk kencing nanah perlaukannya sama namun tidak pakai penambahan gula aren.

\section{KESIMPULAN}

Ditemukan 11 species tumbuhan familia Asteraceae yang dipercaya masyarakat dapat mengobati 12 jenis penyakit.penyakit yang dapat diobati dengan obat tunggal yaitu 8 jenis penykit dan penyakit yang dapat diobati untuk ramuan obat ada sebanyak 4 jenis penyakit.

\section{DAFTAR PUSTAKA}

Anjelina, H.S. 2017. Potensi Familia Asteraceae Sebagai Obat Tradisional Di masyarakat Etnis Simalungun Kabupaten Simalungun Provinsi Sumatra Utara. Sekolah Tinggi Ilmu Kesehatan Senior Medan. BioLink Vol. 4 (1) Agustus 2017 (p-ISSN : 2356-458x e-ISSN: 2597-5269). 
Boesri, H. 1994. Pemanfaatan Tanaman Dalam Penanggulangan Malaria. Artikel. Stasiun Penelian Vektor Penyakit, Selatiga (Media Litbangkes Vol 4 No.01/1994).

Des, M., Rizki, R., dan Hidayati, H.,(2018, april) Ethnobotany In Traditional Ceremony at Kanagagian Sontang CubadakPadang Gelugur Subdisctrict, Pasaman Disctrict. In IOP Conference Series, Materials Science and Enggineering (Vol. 335 No.1,p.010218) IOP Publishing.

Efremila. 2015. Studi Etnobotani Tumbuhan Obat Oleh Etnis Suku Dayak Di Desa Kayu Tanam Kecamatan Mandor Kabupaten Landak. Fakultas Kehutanan Universitas Tanjungpura Jalan Imam Bonjol Pontianak.

Fernando, O. 2014. Studi Pemanfaatan Tumbuhan Berkasiat Obat di Kecamatan Luhak Nan Duo Kabupaten Pasaman Barat. Skripsi. Program Studi Pendidikan Biologi STKIP PGRI Sumatra Barat.

Gbadamosi, T. 2012. Evolution Of Antibacterial Activity of ixEtnobotanycals Used in the Treatment of Infectious Diseases in Nigeria. Botany Research International. 5(4). 8389.

Leilani, I., Rizki, R., \& Sari, D. (2017). Ethnobotani Study on Mangrove Forests in Padang City and Pariaman City. Ethnobotani Study on Mangrove Forests in Padang City and Pariaman City, 1(2).

Jabar, A.S. 2014. Khasiat Obat dan Manfaat Dari Kembang Kertas. Asgar.or.id

Kusumawati I, Djatmiko W, Rahman A. 2003. Eksplorasi Keragaman Dan Kandungan Kimia Tumbuhan Obat Di Hutan Tropis Gunung Arjuno. Fakultas Farmasi Universitas Airlangga.

Maimulyanti A, Restu A.P, Safrudin I. 2016. Chemical Composition Phytochemical Screening and Antioxidant Activity of Acmella uliginosa (Sw) Cass Leaves. Dapertement Of Chemical Analysis, Academy of Analiytical Chemistry (AKA). Bogor. (Indines. J. Cem., 2016, 16(2). 162-174).

Milda, T., \& Leilani, I. (2012). STUDI ETNOBOTANI PADA HUTAN MANGROVE DI KENAGARIAN MANGGUANG KOTA PARIAMAN. e-Jurnal Mahasiswa Prodi Pend Biologi 2012, 1(1).

Mukhraini. 2014. Ekstaksi, Pemisahan Senyawa, dan Identifikasi Senyawa Aktif. Program Studi Farmasi Fakultas Ilmu Kesehatan UIN Alaudin. Makasar (Jurnal Kesehatan Vol. VII No 2/2014).

Riswan, S. dan Andayaningsih D. 2008. Keanekaragaman Tumbuhan Obat Yang Digunakan Dalam Pengobatan Tradisional Masyarakat Sasak Lombok Barat. Fakultas Biologi Universitas Nasional. (Jurnal farmasi Indonesia Vol. 4 No. 2 Juli 2008:96-103).

Muslihah, F. 2007. Tanaman Obat Keluarga (TOGA). Jakarta : Penebar Swadaya.

Natoatmodjo, S. 2010. Promosi Kesehatan Teori dan Aplikasnya. Cetakan 2. Jakarta : Rineka Cipta. 
Riani V.S, Mona P.W, Awaloei H. 2013. Uji Efek Analgesik Ekstrak Daun Beluntas ( Plucea indica (L.) Less.) Pada Mencit (Mus musculus). Skripsi. Fakultas Kedokteran Universitas Sam Ratulangi Manado.

Riswan, S. dan Andayaningsih, D. 2008. Keanekaragaman Tumbuhan yang Digunakan Dalam Pengobatan Tradisonal Masyarakat Sasak lombok Barat. Fakultas Biologi Universitas Nasional. Jurnal Farmasi Indonesia Vol. 4 No. 2 Juli 2008 : 96-103.

Rizki, Fernando O, Nursyahra. 2017. Etnofarmakologi Tumbuhan Familia Asteracese Di Kabupaten Pasaman Barat. Prosiding Seminar Nasional BioEti 4 dan Kongres PTTI ke 12.

Sari A, Linda R, Lovadi I. 2015. Pemanfaatan Tumbuah Obat Pada Masyarakat Suku Dayak Jangkang Tanjung Di Desa Ribau Kecamatan Kapuas Kabupaten Sanggau. Program Studi Biologi. Fakultas FMIPA UNIversitas Tanjungpura. Pontianak (Potobiont (2015) Vol. 4 (2): 1-8)

Rizki, R., \& Leilani, I. (2018). Etnofarmakologi Tumbuhan Familia Rhizophoraceae oleh Masyarakat di Indonesia. Jurnal Bioconcetta, 3(1).

Sukarno A.S, Sulaeman S.M, dan Pitopang R. 2014. Jenis Jenis Tumbuhan Suku Asteraceae Di Desa Mataue Kawasan Taman Nasional Lore Lindu. Jurnal Biologi FMIPA Universitas Tadulako. (Online Jurnal Of Natural Science, Vol 3(3) : 297-312, Desember 2014).

Sukmawati, Hadi H, aminah. 2017. Potensi Senyawa Flavonoid Daun Afrika (Vernonia amygdalina Del.) Asal Ternate Sebagai Antioksidan.fakultas Farmasi Universitas Muslim Indonesia. Makasar (As-Syifaa Vol 09(02) : Hal.195-200, Desember 2017 (ISSN : 2085-4714).

Suryadarma, 2008. Etnobotani. Diklat Kuliah Jurusan Pendidikan Biologi MIPA : Universitas Negri Yogyakarta.

Syukur, C. dan Hernani. 2003. Budidaya Tanaman Obat Komersial. Jakarta : Penebar Swadaya.

Tambaru, E. 2017. Keragaman Jenis Tumbuhan Obat Indigenous Di Sulawesi Selatan. FMIPA Universitas Hasanuddin. Makasar (Jurnal Alam dan Lingkungan 8 (15) (2017) 7-13 